\title{
DO DISCURSO PARA A GRAMÁTICA, DA GRAMÁTICA PARA O DISCURSO: UMA ENTREVISTA COM SEBASTIÃO JOSUÉ VOTRE
}

\author{
Edair Maria Görski | Lattes | edagorski@hotmail.com \\ Universidade Federal de Santa Catarina
}

Leandra Cristina Oliveira | Lattes | leandraletras@hotmail.com

Universidade Federal de Santa Catarina

Tatiana Schwochow Pimpão | Lattes | tatianapimpao@furg.br Universidade Federal do Rio Grande

\section{Introdução}

Sebastião Josué Votre é professor titular e livre-docente da UFRJ e professor associado IV da UFF, aposentado em ambas as instituições. Foi professor titular da Universidade Gama Filho até 2013, professor visitante na UERJ e pesquisador na UNISUAM-RJ.

Fez Mestrado em Linguística e Letras (1974) na PUC-RS, Doutorado em Letras na PUC-RJ (1978) e conquistou a Livre-docência em Linguística na UFRJ (1987). Desenvolveu estudos de pós-doutorado na Universidade da Pensilvânia (1980), na Universidade da Califórnia Los Angeles (1986), na Universidade de Essex, Inglaterra (1988), na Universidade Laval (1992), na Universidade da Califórnia Santa Barbara (1999) e na Universidade de Strathclyde, Escócia (1999).

Integrou, entre outros, os projetos de pesquisa: "Evidências de continuidade semântica: do português medieval ao contemporâneo" (2004-2006), “Continuidade, variabilidade e mudança no português arcaico e contemporâneo" (1998-2003), Discurso \& Gramática (1988-1995), Mecanismos Funcionais do Uso Linguístico (1980-1988), Variação e Mudança no Português do Brasil (1980-1988) e Léxico e sintaxe das crianças do Estado do Rio de Janeiro (1979-1981). Idealizou e coordenou durante três anos o primeiro Curso de Especialização em Ensino de Leitura e Produção Textual a Distância, no CEDERJ, para professores da rede estadual.

Nos últimos cinco anos, vem trabalhando na produção de manuais para leitura crítica e escrita acadêmica. Em 2020 voltou a participar das atividades do grupo de estudos Discurso \& Gramática, por ele fundado na UFRJ em 1992.

Tem cerca de duas centenas de publicações incluindo artigos em periódicos, livros e capítulos de livros (mais de cem artigos acadêmicos publicados; mais de trinta livros 
publicados e/ou organizados; mais de quarenta capítulos de livros). Formou mais de uma centena de mestres e doutores.

A vasta experiência acadêmica de Votre - especialmente o fato de ele, juntamente com Anthony Naro, ter praticamente introduzido no Brasil, na década de 1980, a abordagem funcionalista de vertente norte-americana - justifica nossa escolha em abrir o número temático Gramática do uso da Revista Working Papers em Linguistica com esta entrevista.

Neste texto, a leitora e o leitor terão acesso a uma espécie de síntese do percurso acadêmico de Votre, uma linha temporal imaginária que emerge de suas respostas gentilmente a nós concedidas nesta entrevista. $O$ ponto inicial, como não poderia deixar de ser, marca seus primeiros passos no campo teórico do Funcionalismo linguístico da costa oeste norte-americana, em diálogo com grandes nomes como Sandra Thompson, Talmy Givón e Gillian Sankoff. Nesta conversa, também entram em cena temáticas como: (i) o debate repaginado nomeado pelo entrevistado como novo Funcionalismo Linguístico; (ii) uma retrospectiva ao surgimento do Grupo de Estudos Discurso \& Gramática, seus objetivos, parcerias e alguns resultados alcançados; (iii) uma exposição sobre as interfaces teóricas propostas nos últimos anos que envolvem o funcionalismo linguístico de vertente norte-americana, e sobre os principais desafios teóricos e descritivos para os estudos funcionalistas do Português do Brasil; e (iv) as justificativas e motivações que o levam a distanciar-se dos estudos funcionalistas, voltando-se, em suas palavras, ao "alargamento da atenção para outros aspectos sociais que interferem na formação da gramática”.

Com esta apresentação de um linguista multifacetado, como multifacetado e plural é o próprio Funcionalismo, reforçamos nosso convite à incursão da leitura deste número temático.

\section{Entrevista}

Görski, Oliveira e Pimpão: Você tem formação na área de Sociolinguística e sua tese de doutorado (1978), orientada por Anthony Naro, tratou de variação fonológica na fala do Rio de Janeiro. Como surgiu seu interesse pelo Funcionalismo linguístico de vertente norte-americana?

Sebastião Votre: ${ }^{1}$ Na sociolinguística correlacional, trabalhamos com duas variantes de sentido supostamente equivalente, associadas a fatores linguísticos e não linguísticos. No caso do estudo sobre o travador de sílaba -r, sobretudo em final de palavra, na fala dos

\footnotetext{
${ }^{1}$ Agradeço a colaboração de Angélica Furtado, Mariângela Rios, Maura Cezario e Roberto de Freitas na revisão desta entrevista.
} 
analfabetos do Rio de Janeiro, avaliamos quais eram os principais fatores linguísticos e sociais que favoreciam sua manutenção ou recuperação, e quais contribuíam para seu desaparecimento. Labov fizera estudo sobre o -r em Nova Iorque, e mostrava que a vibrante final estava em processo de recuperação. Celso Cunha, entre nós, levantava hipótese similar, no português do Brasil.

Nosso contato com o grupo de Sandra Thompson, na UCLA, levou a um deslocamento do eixo, para análise do comportamento de uma só forma, levando em conta os fatores que fizessem sentido, sem mais dar atenção para variantes dessa forma. Também lá, travamos contato mais estreito com as postulações de Talmy Givón, com seus estudos sobre a trajetória do discurso para a gramática, e as ideias de Gillian Sankoff, sobre as origens da sintaxe no discurso, com dados do Tok Pisin, em que a função comunicativa a ser conseguida presidia o arranjo da forma. Os estudos de ambos justificavam o conceito de língua de Dwight Bolinger, como realidade de domínio maleável, que se adapta continuamente para dar conta de razões comunicativas. Deriva daí também a atenção para o papel da iconicidade diagramática, como relação de um para um entre função e forma: os estudos do Tok Pisin, então em pleno desenvolvimento, ofereciam evidência de que, em certos contextos de pidginização, as formas originadas na interação guardam relação estreita com o seu conteúdo. Foi em contato com essas ideias que forjamos para nosso programa de estudos a expressão discurso \& gramática.

O movimento funcionalista contribuiu para um deslizamento progressivo da atenção ao conteúdo para atenção à forma em si, e para afrouxamento da relação icônica, e consequente crescimento da arbitrariedade. Parte desse movimento derivou para o estudo dos processos de gramaticalização, ou organização autônoma da gramática.

Portanto, fomos nos afastando dos estudos sobre como surgia e se gramaticalizava uma forma, bem como nos afastamos da ideia concomitante de que a sintaxe, em si, não existe, como na formulação radical de Erica Garcia, que postulava um discurso sem sintaxe. Nós nos encaminhamos para uma formulação mais sintática, em contato com ideias mais refinadas sobre características da estrutura. Tratava-se de uma abordagem de análise no discurso e não "do discurso" e por isso mais atrelado ao estudo da forma, assim como ao da função.

Görski, Oliveira e Pimpão: Durante algum tempo você trabalhou em colaboração com Anthony Naro. Em 1989, foi publicado um artigo de vocês na revista D.E.L.T.A. "Mecanismos funcionais do uso da língua" - que suscitou um frutífero debate acerca de funcionalismo versus formalismo. A revista publicou uma sequência de discussões: em 
1990, Milton do Nascimento questiona algumas das ideias apresentadas por Votre \& Naro, analisando-as à luz da abordagem gerativa; em 1991, Mike Dillinger retoma as discussões, propondo como solução uma teoria "global". Como você avalia o impacto desse debate no desenvolvimento da linguística no Brasil?

Sebastião Votre: Nosso foco era a sintaxe no discurso, embora na época eu pensasse que poderia haver uma gramática do discurso, o que o movimento da análise modular do discurso acabou desautorizando. $\mathrm{O}$ debate se repagina, agora, mas dentro do próprio funcionalismo que inauguramos, com atenção genuína para o pareamento entre forma e sentido, no construcionalismo e nas vertentes de matiz cognitiva. Por outro lado, os movimentos de raiz se consolidam em novos estudos sobre conectores e operadores discursivos, em que se acrescentam categorias analíticas relevantes, além das confirmadas em seu poder explicativo. Num certo momento convivíamos com estudiosos da linguística textual, sob influência de Marcuschi e Koch, entre outros pesquisadores.

Görski, Oliveira e Pimpão: Como você considera, hoje, a relação entre essas duas abordagens - funcionalismo e formalismo?

Sebastião Votre: O debate sobre mecanismos funcionais do uso da língua começou por iniciativa dos formalistas. Milton do Nascimento fazia eco a uma força de resistência, por parte dos gerativistas de então, para quem o estudo relevante da sintaxe deveria ser gerativo. Miriam Lemle, entre nós na UFRJ, brincava dizendo que nosso movimento não perduraria.

Entendo que há razões robustas para que o funcionalismo de raiz se aproprie de ferramentas que propiciem uma descrição mais clara e com capacidade explanatória e descritiva robusta no que diz respeito aos aspectos de forma e de sentido com aumento de capacidade explicativa e abrangência do escopo das categorias analíticas.

Conte-se também a influência de novas incursões de funcionalistas clássicos, como Traugott, que se associou a Trousdale, o que contribui para alguns grupos funcionalistas adotarem uma abordagem mais sintaticista, como construcionalismo e manifestações do que entendo como cognitivismo funcional, a exemplo de Diessel.

Por outro lado, voltou a ter força a ideia da frequência, que se anunciava com a correlação entre o que os falantes mais utilizam e o que a gramática mais prontamente codifica.

Görski, Oliveira e Pimpão: Você foi o fundador e primeiro coordenador do Grupo de Estudos Discurso \& Gramática, na UFRJ, no início da década de 1990. O grupo envolvia, à época, pesquisadores de várias instituições: UFRJ, UFF, UFRN, UFJF e FURG. Qual era o objetivo principal do $D \& G$ ? Como você avalia o impacto do $D \& G$ nas pesquisas 
funcionalistas que se desenvolveram em diferentes instituições brasileiras a partir de então?

Sebastião Votre: O objetivo imediato era construir um corpus para trabalho dos meus orientandos, entre os quais Edair Gorski e Attila Louzada, uma vez que havia restrições no uso do corpus do Programa de Estudos do Uso da Língua, PEUL, que Naro, outros colegas e eu tínhamos fundado na UFRJ no final da década de 1970.

O objetivo mais duradouro, entretanto, era contribuir com o que se fazia na costa oeste americana, mais precisamente Santa Barbara, Los Angeles e em Oregon, na formulação de teorias e metodologias de análise das origens da gramática no discurso. Nós vínhamos trabalhando com conceitos como morfologização e sintaticização, desde o estágio na UCLA, em que testávamos ideias de Talmy Givón e Gillian Sankoff, decorrentes de seus estudos sobre pidginização. O trabalho com Sandra Thompson, em 1986, me permitiu testar o que ela e Hopper haviam formulado sobre transitividade no discurso e na gramática, e sobre os estudos iniciais a respeito da sintaticização, em que se discutia até que ponto a gramática era sólida, e até que ponto era historicização dos usos, o que Hopper identificava como Emergent grammars.

Mas foi no estágio de 1992, na Université Laval, com Diane Vincent, que se avolumaram e se consolidaram as ideias de um projeto maior de análise de fenômenos relativamente abandonados pelas análises de então. No caso de Vincent, o estudo era sobre os pontuantes, como là, oui, e par example. Seguindo a linha de pesquisa do grupo de Genebra, ela afirmava que tais partículas não tinham sentido algum. Em nosso grupo, no Rio, trabalhávamos com as margens da gramática e procurávamos resquícios de sentido associados a essas partículas denotativas.

Na própria ULAVAl, produzi um artigo com Diane Vicent e Marty Laforest, que intitulamos Grammaticalisation et post-grammaticalization, em que reformulamos a acepção do grupo de Vincent.

O relatório do estágio, intitulado Linguística funcional, teoria e prática, procurava dar conta das ideias que lá pesquisei, nos dois volumes de Approaches to grammaticalization.

Görski, Oliveira e Pimpão: Nos últimos anos, diferentes interfaces têm sido propostas envolvendo o funcionalismo linguístico de vertente norte-americana. Nos referimos, por exemplo, à articulação entre gramaticalização e variação, tratada no Brasil sob uma ótica sociofuncionalista (Naro \& Braga, 2000; Tavares, 2003; Görski \& Tavares, 2017, entre outros); e aos novos caminhos da Linguística Funcional Centrada no Uso, em aproximação com a Linguística Cognitiva, incorporando a abordagem construcional da gramática 
(Rosário \& Oliveira, 2016, entre outros). Como você vê essa busca por diálogo entre diferentes campos teóricos?

Sebastião Votre: Considero o diálogo produtivo. Desde nossa primeira produção como grupo, que foi Gramaticalização no português do Brasil, em 1996, os membros do grupo Discurso \& Gramática refinaram e reformularam conceitos, testaram e ajustaram métodos de análise, consolidaram propostas de metaforização, avançaram na abordagem dos mecanismos de metonimização, passaram a focalizar com mais detalhe e circunstância a forma e a formalização do aparato analítico, conferiram mais atenção aos possíveis efeitos da frequência na gramaticalização e vêm testando princípios, modelos e estratégias de análise de motivação cognitiva.

Görski, Oliveira e Pimpão: Quais os principais desafios teóricos e descritivos para os estudos funcionalistas do Português do Brasil, desde a emergência desse campo de investigação à atualidade?

Sebastião Votre: São três os desafios. O primeiro é a produção de uma gramática, a exemplo do que fez Givón, em 1984, no funcionalismo de raiz, e do que agora acaba de fazer Diessel, na versão corrente que incorpora construcionalização e aportes das ciências da cognição.

Isso nos fará continuar a nos ocuparmos das "margens" da gramática, dos conectores, das frases feitas, dos idiomatismos, dos chunks e, consequentemente, mantendo o foco nos estudos com atenção para frequência de ocorrência. Por outro lado, precisamos fazer a passagem dos tokens, para os types, com focalização da atenção nas estruturas sintáticas maiores.

O segundo é um dicionário de linguística centrada no uso, que cubra as principais manifestações teóricas, seus representantes e suas principais linhas de pesquisa funcionalista. Por fim, precisamos propor e implementar um programa de aplicações de nossa linha de estudos aos desafios do ensino da língua, nos níveis básico e superior.

Görski, Oliveira e Pimpão: Percebe-se, em seu Curriculum Lattes, que a partir do ano 2000 seu campo de atuação passou a se distanciar dos estudos funcionalistas. Que fatores o levaram a esses novos caminhos?

Sebastião Votre: São vários os fatores que, numa espécie de deriva, me encaminharam para dimensões educacionais e políticas na abordagem das questões linguageiras.

O primeiro foi a troca de departamento. Em 1995 me aposentei no departamento de linguística da UFRJ e fiz concurso para o departamento de língua portuguesa da UFF. Concentrei-me no ensino de fonologia, o que me levou a envolvimento maior com a aná- 
lise do Appendix probi e com documentos do português antigo. Envolvi-me na análise crítica do discurso dos textos medievais, em especial os de Dom Duarte. Comecei, então, a produzir análise da forma, do conteúdo e do discurso, com foco no ensino de gêneros acadêmicos.

Foi também de natureza profissional o segundo fator que me levou, de vez, para análise do discurso sobre características dos gêneros acadêmicos. A partir de 2009, passei a atuar como consultor da fundação CECIERJ, e com Vinicius Carvalho Pereira redigi um caderno didático, em versão ebook, intitulado Redação de textos acadêmicos, que passou a ser utilizado nos cursos a distância, promovidos por aquela fundação.

Em 2011, atendendo a pedido da reitoria da UFF, produzi outro trabalho em grupo, Desenvolvendo a competência comunicativa em gêneros da escrita acadêmica, para alunos calouros. Foram meus parceiros Vinicius Carvalho Pedreira e José Carlos Gonçalves.

Por sugestão de Mariângela Rios de Oliveira e Victória Wilson, reuni e revisei parte dos trabalhos que produzi com colegas, na trajetória funcionalista, em obra de 2012, na UFF, intitulada $A$ construção da gramática. Os três primeiros capítulos retomam o debate que Anthony Naro e eu travamos com Milton do Nascimento. Nos outros capítulos, constam textos escritos em parceria com Sylvie Dubois, Mariângela Rios de Oliveira, Maria Angélica Furtado da Cunha, Victória Wilson e o saudoso Mário Martelotta. Nessa coletânea constam dois capítulos meus. O primeiro é sobre versão reduzida e revisada do texto utilizado para o concurso de titular de linguística da UFRJ, Uma proposta de base cognitiva da gramática. O segundo é sobre Construção da gramática em textos medievais.

Como terceiro fator, quero mencionar a busca de relevância do retorno social que, no eixo dos estudos de natureza sociolinguística, sempre me acompanhou. Passou a crescer o lado social, com o alargamento da atenção para outros aspectos sociais que interferem na formação da gramática, sobretudo no grupo de estudos interdisciplinares da UCSB.

Quero mencionar também o peso do contexto acadêmico em que me fui envolvendo. O interesse por questões de psicologia e filosofia da linguagem resultou de minha convivência com antropólogos, como Hugo Lovisolo, com psicólogos sociais, como Serge Moscovici, sociólogos, como Bruno Latour, filósofos da linguagem como Richard Rorty, e linguistas que fazem análise do discurso, como Norman Fairclough. Esta convivência me trouxe de volta para o discurso.

O contato com estudos de natureza crítica, por conta de orientação de teses sobre modalizadores e componentes de natureza argumentativa, me desvendou o lado opressor da linguagem, e passei a prestar atenção para categorias como marcas de empoderamento e de anulação. 
Nos três últimos anos, tentando ser fiel aos pontos salientes da minha memória discursiva, aceitei o desafio de contribuir para a emancipação das pessoas via linguagem. Nessa linha, envolvi-me, em 2018, com Rosana da Silva Berg, no gênero memorial, Escrevemos Orientações para a escrita acadêmica - memorial de conclusão de curso.

Examinei a produção da sociolinguística francesa que deu suporte à análise do discurso, e me voltei para categorias analíticas que me ajudam a interpretar hábitos e valores sociais, entre os quais se contam o sexismo, o racismo, o autoritarismo, e o machismo. Essas categorias aparecem no livro Análise do discurso, que produzi em 2019 para o ensino da graduação em Letras, a pedido da Parábola. Esta foi a única obra que produzi sozinho, por exigência da editora.

No momento, com Rosana, trabalho com a categoria do bem viver, na análise dos documentos internacionais fundadores da educação, a exemplo das Declarações de Jomtien, Paris e Córdoba, e de como elas se traduzem nas competências formuladas em dois documentos oficiais brasileiros, a Base Nacional Comum Curricular e a Base Nacional Curricular Formação.

Sintetizando minha trajetória acadêmica, caminhei do discurso para a gramática, procurei entender a interação entre discurso e gramática, encontrei evidências de como a gramática se constrói no discurso, e agora estou de volta, da gramática para o discurso, mas sem abandonar as questões gramaticais. Nesse sentido, aceitei com prazer o convite do $D \& G$ da UFRJ para retornar às atividades do grupo.

Görski, Oliveira e Pimpão: Muito obrigada!

\section{Referências}

DIESSEL, Holger. The grammar network : how linguistic structure is shaped by language use. New York, NY: Cambridge University Press, 2019.

DILLINGER, Mike. Forma e função na linguística. In: D.E.L.T.A., v. 7, n. 1, p. 395-407, 1991.

GIVÓN, Talmy. Syntax - a functional-typological introduction. Amsterdam. J. Benjamins. 1984 (v.I); 1990 (v. II).

GÖRSKI, Edair; TAVARES, M. Alice. O objeto de estudo na interface variaçãogramaticalização. In: BAGNO, M.; CASSEB-GALVÃO, V.; REZENDE, T. F. (Orgs.) Dinâmicas funcionais da mudança linguística. São Paulo: Parábola. 2017. p. 35-63.

MARTELOTTA, Mário Eduardo; VOTRE, Sebastião Josué. CEZARIO, Maria Maura (Orgs.). Gramaticalização no português do Brasil - uma abordagem funcional. Rio de Janeiro. Tempo Brasileiro. 1996. 
NARO, Anthony J.; BRAGA, M. Luiza. A interface sociolinguística/ gramaticalização. Gragoatá, n. 9, p. 125-134, 2000.

NASCIMENTO, Milton do. Teoria gramatical e mecanismos funcionais do uso da língua. In: D.E.L.T.A, v. 6, n. 1, p. 83-98, 1990.

ROSÁRIO, Ivo C. do; OLIVEIRA, Mariângela R. de. Funcionalismo e abordagem construcional da gramática. ALFA, v. 60 (2), p. 233-259, 2016.

TAVARES, M. Alice. A gramaticalização de e, aí, dai e então: estratificação/variação e mudança no domínio funcional da sequenciação retroativo-propulsora de informações - um estudo sociofuncionalista. 2003. 307 f. Tese (Doutorado em Linguística). CCE. Universidade Federal de Santa Catarina, Florianópolis.

VOTRE, Sebastião; NARO, Anthony J. Mecanismos funcionais do uso da língua. In: D.E.L.T.A, v. 5, n. 2, p. 169-184, 1989.

VOTRE, Sebastião. Aspectos da variação fonológica na fala do Rio de Janeiro. 1978. Tese (Doutorado em Letras). PUCRJ, Rio de Janeiro.

VOTRE, Sebastião; CARVALHO PEREIRA, Vinicius; GONÇALVES, José Carlos. Desenvolvendo a competência comunicativa em gêneros da escrita acadêmica. Niterói, Editora da UFF, 2011.

VOTRE, Sebastião. A construção da gramática. Niterói, Editora da UFF, 2012.

VOTRE, Sebastião; BERG, Rosana. Orientações para a escrita acadêmica - memorial de conclusão de curso. Rio, Mauad/FAPERJ, 2018.

VOTRE, Sebastião. Análise do discurso. São Paulo. Parábola. 2019. 